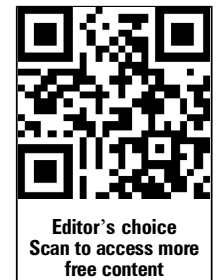

${ }^{1}$ Department of Rehabilitation Sciences and Physiotherapy, Ghent University, Ghent, Belgium ${ }^{2}$ Division of Musculoskeletal Physiotherapy, Department of Health Sciences, Artesis University College Antwerp, Antwerp, Belgium

Correspondence to Dr Barbara Cagnie, Department of Rehabilitation Sciences and Physiotherapy, Ghent University, De Pintelaan 185, 3B3, 9000 Ghent, Belgium; Barbara.cagnie@ugent.be

Received 4 January 2013 Revised 15 April 2013 Accepted 20 April 2013 Published Online First 18 May 2013
To cite: Cools AMJ Struyf F, De Mey K, et al. Br J Sports Med 2014;48: 692-697.

\title{
Rehabilitation of scapular dyskinesis: from the office worker to the elite overhead athlete
}

\author{
Ann M J Cools, ${ }^{1}$ Filip Struyf, ${ }^{2}$ Kristof De Mey, ${ }^{1}$ Annelies Maenhout, ${ }^{1}$ Birgit Castelein, ${ }^{1}$ \\ Barbara Cagnie $^{1}$
}

\section{ABSTRACT}

The scapula functions as a bridge between the shoulder complex and the cervical spine and plays a very important role in providing both mobility and stability of the neck/shoulder region. The association between abnormal scapular positions and motions and glenohumeral joint pathology has been well established in the literature, whereas studies investigating the relationship between neck pain and scapular dysfunction have only recently begun to emerge. Although several authors have emphasised the relevance of restoring normal scapular kinematics through exercise and manual therapy techniques, overall scapular rehabilitation guidelines decent for both patients with shoulder pain as well as patients with neck problems are lacking. The purpose of this paper is to provide a science-based clinical reasoning algorithm with practical guidelines for the rehabilitation of scapular dyskinesis in patients with chronic complaints in the upper quadrant.

\section{INTRODUCTION}

Chronic neck and shoulder pain are among the three most prevalent musculoskeletal disorders in the general population, with more than $60 \%$ of individuals suffering neck/shoulder pain at some stage throughout life. ${ }^{12}$ Although great variability in prevalence figures on neck/shoulder pain is reported, it can be seen as an important medical and socioeconomic problem in western society. ${ }^{3}$ In addition, its prevalence is known to increase with computer workload, or with participation in an overhead sport. $^{45}$

There is a strong relationship between chronic neck and shoulder pain and dysfunction of the scapula. The scapula functions as a 'bridge' between the shoulder complex and the cervical spine and plays a very important role in providing both mobility and stability to the neck/shoulder region. Since the first clinical papers in the literature regarding the role of the scapula in athletic shoulder function and the possible relation to shoulder pain in the overhead athlete, there has been a growing interest in the scapular kinematics, scapular evaluation and intervention principles and programmes. $^{6-8}$ Although the association between abnormal scapular positions and motions and glenohumeral joint pathology has been well established in the literature and summarised in recent review articles, studies investigating the relationship between neck pain and scapular dysfunction have only recently begun to emerge. ${ }^{9}{ }^{10}$ It is clinically recognised that patients with mechanical neck pain may exhibit similar alterations in scapular orientation and motion to that observed in patients with painful shoulder disorders. This is feasible in view of the close relationship of the scapula through the axioscapular muscles with the cervical and midthoracic portion of the spine. ${ }^{11} 12$

Numerous scientific and review papers have been published regarding the biomechanical background of scapular dyskinesis, the association with shoulder pathologies and the clinical assessment of scapular dysfunction. ${ }^{6} 91013 \quad 14$ Although several authors have emphasised the relevance of restoring normal scapular kinematics through exercise and manual therapy techniques, to date, no paper has thoroughly approached overall scapular rehabilitation guidelines decent for both patients with shoulder pain as well as patients with neck problems. ${ }^{9}{ }^{13}{ }^{15-17}$ However, rehabilitation guidelines should be specified since, within these groups of patients, the physical conditioning requirements are not homogeneous: the demands on cervical and axioscapular muscle function in an elite overhead athlete will be different from those of a storeman lifting heavy boxes repetitively above chest level or from those required by an office worker working daily on a computer.

Therefore, the purpose of this paper is to provide a science-based clinical reasoning algorithm with practical guidelines for the rehabilitation of scapular dyskinesis in patients with chronic complaints in the upper quadrant, in particular shoulder and cervical spine disorders. ${ }^{15}$ These guidelines may help the clinician to put the rehabilitation of scapular dyskinesis into a precise perspective of the thorough treatment of shoulder and/or neck dysfunction. 151819

\section{SCAPULAR DYSKINESIS IN RELATION TO NECK AND SHOULDER PAIN}

There is a body of evidence suggesting that patients with impingement symptoms and glenohumeral instability consistently show altered scapular kinematics. ${ }^{20-28}$ With respect to scapular orientation in the resting position, it has also been demonstrated that individuals with neck pain may display altered postural behaviour, especially when performing prolonged sitting tasks, such as during computer use. $^{29}$ Increased cervical and thoracic curves and a slouched posture are known to affect scapular orientation, shoulder muscle strength and shoulder range of motion. ${ }^{30-32}$ Scapular dynamic stability has primarily been investigated in association with shoulder pathologies where a reduced clavicle retraction, scapular upward rotation, scapular posterior tilt and increased clavicle elevation have been reported. ${ }^{9}$ Recently, Helgadottir et al ${ }^{33} 34$ demonstrated a significantly reduced clavicle retraction on 
the dominant side in patients with insidious onset neck pain and whiplash-associated disorders (WAD) both at rest and during arm elevation.

These changes in scapular kinematics can be attributed not only to altered scapular recruitment patterns (eg, altered serratus anterior muscle activity) or muscle performance (eg, force imbalance in the upper and lower trapezius muscle), but also flexibility deficits in the soft tissue surrounding the scapula may restrict normal scapular movement during daily activity and sport-specific movements. ${ }^{6} 2035-39$

\section{Lack of soft tissue flexibility}

With respect to soft tissue inflexibility, tightness of the m pectoralis minor and posterior glenohumeral capsular stiffness has been established in relation to abnormal scapular position. Increased scapular internal rotation, as well as increased anterior tilting, has been demonstrated in healthy individuals with a short $\mathrm{m}$ pectoralis minor. ${ }^{40}{ }^{41}$ Subjects with posterior shoulder stiffness (evaluated by measuring the passive glenohumeral internal rotation range of motion) have been found to have greater scapular anterior tilt compared to subjects with the normal glenohumeral internal rotation range of motion. ${ }^{39}$ These alterations in scapular position are similar to the scapular deviations, established in patients with impingement symptoms. $^{20} 24$ Tyler et $a l^{42}$ quantified posterior shoulder tightness and motion loss in patients with shoulder impingement. The authors also found that correction of posterior shoulder tightness was associated with symptom resolution in patients with impingement symptoms. ${ }^{43}$ In addition, posterior shoulder and $\mathrm{m}$ pectoralis minor stiffness have been identified as a possible risk factor for chronic shoulder pain in overhead athletes. ${ }^{44-47}$ In summary, evidence suggests a significant association between stiffness of soft tissue surrounding the scapula, scapular dyskinesis and chronic neck/shoulder complaints. However, stiffness of other structures possibly altering scapular kinematics, such as the $\mathrm{m}$ levator scapulae, $\mathrm{m}$ latissimus dorsi, the glenohumeral external rotator muscles and the $\mathrm{m}$ rhomboidei, has not yet been quantified, but could possibly contribute to motion restriction of the scapula, based on scapular dyskinesis.

\section{Lack of muscle performance}

Several authors have demonstrated altered muscle activity patterns in the scapular muscles in patients with shoulder impingement. These include altered muscular activity or strength, and changes in the timing properties of the serratus anterior (SA), the upper (UT), middle (MT) and lower (LT) portions of the trapezius. In particular, researchers consistently demonstrated a decreased strength in SA, hyperactivity and early activation of UT (resulting in a shrug-excessive elevation of the shoulder girdle during arm elevation), and decreased activity and late activation of MT and LT. 35 36 48-51

Most studies investigating axioscapular muscle function in neck pain have focused on UT. Changes in the behaviour of UT during typing or other similar upper limb tasks have been shown in patients with both insidious onset and traumatic onset neck pain in clinical ${ }^{52-56}$ as well as in experimental pain studies. ${ }^{57}$ Zakharova-Luneva et $a l^{58}$ and Wegner et al ${ }^{59}$ evaluated the behaviour of all three portions of trapezius muscle in patients with chronic mechanical neck pain. During a typing task, the neck pain patients generated greater activity in the middle trapezius and less activity in the lower trapezius compared to the control group, whereas during isometric shoulder abduction and external rotation significantly greater levels of LT electromyography (EMG) signals were observed in the patient group and no changes in UT and MT. ${ }^{58} 59$

Recently, some studies have also demonstrated altered activity of SA in patients with cervical disorders, during different arm elevation tasks using surface EMG and mfMRI. ${ }^{60}{ }^{61}$ Helgadottir et $a l^{60}$ demonstrated a significantly delayed onset of muscle activation and less duration of muscle activity of SA on both sides during arm elevation. O'Leary et $a l^{61}$ demonstrated a different activation pattern between the upper and lower parts of SA during elevation in a healthy control group, which was not different in subjects with mechanical neck pain.

Scapular dyskinesis has been identified not only in patients with shulder pathology, but also in healthy overhead athletes as a sport specific adaptation. ${ }^{62-67}$ Some studies demonstrate sport-specific adaptations in favour of scapular stability, showing stronger scapular muscles and favourable scapular positioning and movement patterns, ${ }^{636466}$ whereas others demonstrated scapular abnormalities, possibly increasing the risk for chronic shoulder pain in this population, for instance, a lack of upward rotation or decreased flexibility of the $\mathrm{m}$ pectoralis minor muscle. $^{62}{ }^{65-67}$ On the level of muscle strength, recent studies indicate a relative weakness of the stabilising muscles of the scapula (in particular, MT and LT) compared to the prime movers (UT) in adolescent overhead athletes. ${ }^{66}$ These data might help the clinician to identify the possible risk factors for shoulder pain and develop preventive training programmes.

\section{CAUSE-CONSEQUENCE RELATIONSHIP BETWEEN SCAPULAR DYSKINESIS AND NECK OR SHOULDER PAIN}

There is no consensus about the cause-consequence relationship between scapular dyskinesis and shoulder or neck pain. Several mechanisms can potentially contribute to alterations in scapular kinematics. ${ }^{9}$ These include pain, soft tissue stiffness, muscle activation or strength imbalances, muscle fatigue and thoracic posture. It is unclear whether the alterations found in scapular kinematics are compensatory or contributory to neck/shoulder pathology. Recently, a first prospective study was published showing that scapular dyskinesis, based on visual observation, is a risk factor for shoulder pain during the season in professional rugby players. ${ }^{67}$ Possibly, scapular dyskinesis predisposes the subject to develop neck/shoulder pain, but once the abnormality presents, scapular dyskinesis may be exacerbated by paininhibition mechanisms. The latter is often found in clinical practice. Bilateral scapular abnormal positioning and movement patterns (suggesting the primary cause for shoulder pain) are frequently observed during clinical examination, but to a worse degree on the painful side (suggesting scapular dyskinesis being exacerbated by pain). To support this observation, experimental pain studies have demonstrated that pain may directly contribute to the initiation of altered behaviour and function of the axioscapular muscles. ${ }^{57}$ According to a new theory of pain adaptation, it is suggested that during episodes of pain, there is a redistribution of activity within and between muscles, which may have some benefit in the short term (protection from further pain or injury), but there is the potential for adverse long-term mechanical consequences to pain-sensitive tissues. ${ }^{68}$

Irrespective of the direction of cause and effect, it is generally believed that the clinician should focus on scapular evaluation and rehabilitation prior to, or in concordance with, the treatment of the neck or shoulder. Indeed, scapular dyskinesis tends to jeopardise optimal shoulder and neck function through various mechanisms, from decreasing the width of the subacromial space, threatening the fulcrum of the humeral head into the glenoid fossa, to inducing abnormal compressive and shear 
forces in the cervical spine, thus compromising cervical motion and stability. Moreover, scapular dyskinesis may lead to a breakage in the kinetic chain, during overhead athletic activities as well as during prolonged daily activities of the upper quadrant. $^{5} 6$ The scapula plays a very important role as a link between the trunk and the arm, transferring and increasing the energy, power and equilibrium from the lower extremities and the trunk into the arm. ${ }^{69}$ In order to fulfil this task, the scapula has to be in the correct position and all scapular muscles should be activated at the right time in sufficient amount to allow the ground reaction forces to be transferred into the shoulder, and finally into the most distal link of the chain, the hand. Abnormal scapular position and kinematics might lead to a breakage of the functional kinetic chain, putting other links at risk for injury. Therefore, the therapist should always observe, examine and treat scapular dyskinesis in patients with shoulder and neck pain.

\section{REHABILITATION OF SCAPULAR DYSKINESIS}

The intervention strategy for scapular rehabilitation should be based on the clinical evaluation of the patient to permit appropriate goal setting. First of all, a comprehensive initial patient interview is necessary to ascertain the individual's functional requirements and problematic activities. During the physical examination, the therapist should address all possible deficiencies found on different levels of the kinetic chain. Based on the results of clinical assessment, appropriate treatment goals should be set leading to proper rehabilitation strategies.

Although the therapist should address all possible deficiencies found on the different levels of the kinetic chain, this review will not describe all aspects of treatment, but will focus solely on scapular rehabilitation. ${ }^{70}$ Therefore, although considered to be key points in functional shoulder and neck rehabilitation, more proximal links in the kinetic chain, such as thoracic spine mobility and strength, core stability and lower limb function, will not be addressed in these clinical guidelines.
Until now, therapeutic guidelines for treating scapular dysfunction have been developed within the scope of shoulder pain, whereas therapeutic guidelines intended to restore normal scapular function in neck pain patients are mainly based on the results of shoulder studies, owing to the lack of research in this field. However, as it is suggested that similar disturbances in scapular function may be found in both shoulder and neck patients, we believe that the basic treatment approach for both patient groups is mutual, with specific focus pending on the functional demands of the patient. For example, in office workers, rehabilitation will be focused on the correction of the function of the axioscapular muscles, scapular orientation with arms by the side, and during prolonged upper limb activities. However, in overhead athletes, the ultimate treatment goal is to exercise advanced scapular muscle control and strength during sport-specific movements.

Figure 1 summarises a recently published clinical reasoning algorithm that the clinician may use in the treatment of scapular dyskinesis. ${ }^{15}$ In the upper part of the algorithm, a summary is presented of the possible causes for scapular dyskinesis, as described in the first part of this review, whereas in the lower part therapeutic strategies are suggested. The algorithm is further divided into two columns, as a patient presenting with scapular dyskinesis may have flexibility problems or muscle performance problems, or both. Each side of the algorithm needs a specific approach regarding rehabilitation. Flexibility deficits need to be addressed by stretching and mobilisation techniques, whereas muscle recruitment normalisation is the main goal for the patient who has muscle performance problems. If both flexibility deficits and muscle dysfunction are responsible for the scapular dyskinesis, both problems should be addressed. It is imperative to determine whether the flexibility deficits are primary or secondary, based on the relative weakness of the antagonist. In the first case, reducing flexibility problems should precede motor control learning; in the second case, gaining stability may relax the tight muscle.

\section{Scapular Rehabilitation Algorithm}
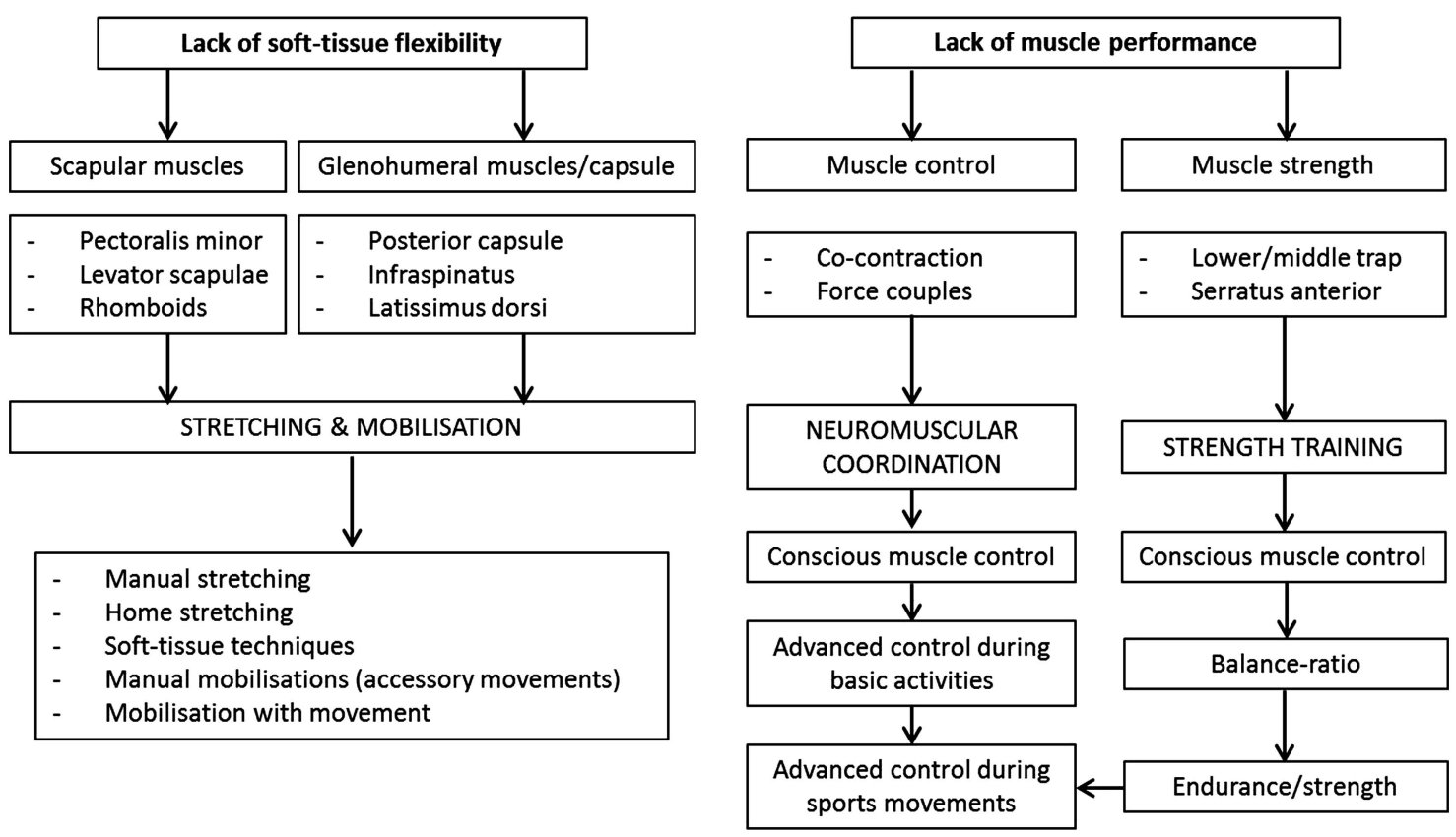

Figure 1 Scapular rehabilitation algorithm. 


\section{Rehabilitation of flexibility deficits}

In case of flexibility problems, these might be located at the scapular muscles, in particular the pectoralis minor and the levator scapulae or at the glenohumeral level, in particular, stiffness and tightness of the posterior shoulder structures, the capsule as well as the glenohumeral external rotator muscles. Both these flexibility deficits may lead to scapular malpositioning, in particular, into anterior tilting and downward rotation. ${ }^{39} 40$

Several stretching techniques have been described to increase the pectoralis minor length. ${ }^{71} 72$ Superior effects of the "unilateral corner stretch' (performing passive horizontal abduction with the shoulder at $90^{\circ}$ of abduction and external rotation) over 'sitting manual stretching' (in which the therapist performs scapular retraction with the shoulder in a neutral position) and 'supine manual stretch' (similar to the unilateral corner stretch, but performed by the therapist with the patient in a supine position) were established in a study on healthy subjects. ${ }^{41}$ However, from a clinical perspective, these stretches (with the exception of the 'sitting manual stretching') put the subject's shoulder into a position possibly causing pain in the case of subacromial or internal impingement. ${ }^{1673}$ In addition, it was found in a cadaveric study that performing scapular retraction in a $30^{\circ}$ forward flexion position results in the largest changes in $\mathrm{m}$ pectoralis minor length. ${ }^{72}$ Therefore in clinical practice, them pectoralis minor might be stretched while performing passive retraction and posterior tilting of the scapula with the shoulder in a neutral or small elevation position and slight external rotation. ${ }^{15}$ In particular, direct pressure on the coracoid process may provide an intense stretching effect on the pectoralis minor.

Although there is a lack in the literature, tension of the levator scapulae is often seen in relation to poor posture and stress. Only a few studies have examined the effect of stretching the levator scapulae on signs and symptoms in patients with shoulder or neck pain. ${ }^{74} 75$ On the other hand, studies investigating the effect of manually treating trigger points in this muscle have recently begun to emerge, although its outcome is still unclear. $^{7677}$

With respect to stretching techniques of the posterior capsule, numerous techniques have been described and studies with respect to their short-term and middle-term effects have been published. ${ }^{43}$ 78-82 Angular stretches, such as the 'sleeper stretch' and the 'cross body stretch', as well as manual therapy (dorsal glides) have been shown to be effective in restoring ROM and increasing the acromiohumeral distance. ${ }^{80-82}$ In addition, it was found that correction of posterior shoulder tightness through stretching and mobilisation was associated with symptom resolution in patients with impingement symptoms. ${ }^{43} 82$

\section{Rehabilitation of muscle performance deficits}

Muscle performance problems may be divided into neuromuscular deficits (a lack of co-contraction and force couple activity) or strength deficits. In the latter, SA, MT and LT have been found to be weak, whereas UT often shows hyperactivity. ${ }^{20} 35-3751$

\section{First stage: conscious muscle control}

In the early stage of scapular training, conscious muscle control of the scapular muscles may be necessary to improve proprioception and to normalise scapular resting position.

In order to selectively activate LT, the 'scapular orientation exercise' has been described. ${ }^{83}$ Priority is first given to the patient attaining active control of scapular orientation, facilitated by the therapist and then practiced by the patient. In this exercise, the patient palpates the coracoid with the contralateral finger and is then asked to pull away the coracoid from his finger and moving the scapula backwards'. It was demonstrated in a three-dimensional scapular movement analysis-study that it is possible to teach a normal subject to consistently reproduce movements of the scapula into a posterior tilt and upward rotation. ${ }^{83}$ In addition, this exercise resulted in a significant increase of scapular muscle activity, and a high correlation between assisted and unassisted exercise was established, indicating that a subject is able to perform this exercise in a home programme. ${ }^{83}$ Wegner $e t a l^{84}$ compared the surface EMG-activity of the three portions of the trapezius in a neck pain group with poor scapular posture during the performance of a functional typing task before and after a scapular postural correction strategy. Following correction of the scapula, activity recorded by the neck pain group was less in MT and higher in LT, which was similar to the control group. Other researchers focused on the use of surface EMG-feedback for learning selective activation of SA and the effect of motor control and movement training on upper limb motor strategies and shoulder function. ${ }^{85-87}$ They showed that conscious movement training with feedback causes immediate but temporary effects on motor strategies and upper limb kinematics. They also showed that patients with shoulder impingement benefit from a 4-week motor control training programme to reduce pain and improve function. ${ }^{75}$ Recently, the value of the scapular orientation exercise prior to dynamic shoulder movements was examined. ${ }^{88}$ This study showed higher surface EMG-activity in the targeted muscles (in particular, MT and LT) during dynamic shoulder exercises when conscious correction of the scapular position was performed prior to the exercise.

It is important to incorporate scapular orientation with spinal posture correction, especially in those patients who have a tendency to drift into a forward head posture, with an increasing thoracic kyphosis and protraction of the shoulder girdle during computer or any other bench work. These posture-correction strategies should be implemented early in the rehabilitation programme and all exercises that are performed in a sitting or standing position should be with a correct posture. To retrain a neutral posture, patients are first taught to achieve a neutral lumbopelvic posture, followed by correction of the scapulothoracic and cervical postures with a subtle gentle 'occipital lift' manoeuvre to position the head in neutral position. It has been proposed that frequent correction to an upright neutral postural position serves two functions. ${ }^{12} 89$ First, it may provide a regular reduction of adverse loads on the cervical joints induced by poor spinal, cervical and scapular postures. Second, it may train the deep postural stabilising muscles of the spine and upper extremities in their functional postural supporting role. Patients are encouraged to perform this exercise repeatedly throughout the day, with the emphasis being on a change in postural habit. Memory joggers may be useful to ensure it becomes a habit.

The use of therapeutic tape can also be helpful in this stage of the rehabilitation, since it has been shown that taping the scapula into extension, posterior tilting and retraction gives proprioceptive feedback to the patient and improves trunk posture and shoulder range of motion. ${ }^{90}$

Second stage: muscle control and strength necessary for daily activities

Depending on the results of the clinical examination, the therapist may decide in the second stage of scapular muscle training to focus more on muscle control and co-contraction (advanced control during basic activities) or muscle strength (in case, for 
instance, manual muscle testing or isokinetic testing shows isolated strength deficit in one or more scapular muscles).

Scapular co-contraction may be trained in basic positions, movements and exercises. As the shoulder girdle functions in both open-chain and closed-chain activities, the muscles should be trained to respond to both situations, by challenging the maintenance of the new scapular position under load, using weight-bearing and non-weight-bearing tasks of the upper limb. These should be consistent with the functional requirements of the patient.

With respect to open-chain activities, Kibler et $a l^{91}$ described specific exercises for scapular control in the early phases of shoulder rehabilitation. The 'low row', 'inferior glide', 'lawnmower' and 'robbery' exercises, as described in their paper, activate the key scapular-stabilising muscles, including the rhomboid, without putting high demands on the shoulder joint, making these exercises appropriate to use in early stages of non-operative as well as in postoperative rehabilitation. Simple exercises mimicking the functional tasks that are problematic to the subjects, like mousing on a computer and lifting bench height, can be implemented in this stage of training. Progression can be made by increasing holding time, repetitions, resistance and speed.

Closed chain exercises are believed to improve dynamic glenohumeral stability through stimulation of the intra-articular and periarticular proprioceptors and enhance co-contraction of the rotator cuff, thus being beneficial in case of shoulder instability. Closed chain training is also very useful when patients have difficulties fixating the scapula to the chest wall. $^{92} 93$ Several studies have been performed investigating scapular muscle activity during closed chain exercises progressing from gently pushing hands on the thighs in upright sitting, to wall sliding exercises and push-ups. ${ }^{94-99}$ The benefit of using unstable surfaces during the push-up position is under debate, with some studies showing beneficial effects on muscle recruitment, ${ }^{99}$ and others showing no significant difference with a stable surface. ${ }^{95}$ In general, closed chain exercises such as push-up variations challenge SA activation, but should be selected with caution in case of impingement related shoulder pain. ${ }^{94}$ Lunden $e t a l^{97}$ showed that the wall push-up, although highly beneficial for SA training, may put the glenohumeral joint in a position that decreases the available subacromial space through aberrant scapular position, and creates a risk for impingement. Hardwick et $a l^{96}$ suggest the wall slide exercise, which is a semiclosed chain exercise as a useful alternative, since it produces similar SA activity compared to other exercises, previously validated in the literature. ${ }^{94} 100$ Uhl et al ${ }^{101}$ concluded from their study that supporting the arm (eg, during 'wall slide' and 'bench slide' exercises) improves SA and LT activity while UT and glenohumeral muscle activity remain low.

For patients with a strength deficit and muscle imbalance in the scapular muscles, selective activation of the weaker muscle parts with minimal activity of the hyperactive muscles is an important component in the second stage of scapular muscle rehabilitation. Because of the observed lack of activity in LT and SA often combined with excessive use of UT, exercises with a low UT/LT, UT/MT and UT/SA ratio are of particular importance. A continuum of functional exercises may be suggested, with increasing activity of the LT, starting with isometric low row exercises', 91 'prone extension at $0^{\circ},{ }^{102}$ 'side lying external rotation', and finally 'prone horizontal abduction with external rotation'. Several studies have been performed identifying exercises that meet this standard of favourable intermuscular and intramuscular activation balance, in open as well as in closed kinetic chain, and several clinical papers extensively describe these exercises. ${ }^{88} 9495103-105$ The push-up plus exercise is very popular for training of SA; however, in view of the high demands of this exercise on the shoulder when performed in the traditional manner, and in view of the fact that the plus-phase (protraction at the end of the movement) is of extreme importance in activating sufficient levels of SA activity, it is recommended to perform the 'elbow push-up'. In addition, the 'dynamic hug', 'supine punch' and 'wall slide exercises' may be beneficial. ${ }^{1696106}$ For intramuscular trapezius training, four exercises have been recommended: side lying external rotation, side lying forward flexion, prone horizontal abduction with external rotation and prone extension. ${ }^{102} 105$ Recently, it was demonstrated that these exercises, having optimal UT/MT and UT/LT ratio in terms of activity level, also guarantee the early activation of LT and inhibition of the latency of UT. ${ }^{105}$ Another way to increase muscle activity in the weaker muscles is by integrating kinetic chain components into the exercise. Increased activity in SA can be obtained if the ipsilateral leg is extended during push-up plus exercises, whereas extension of the contralateral leg improves LT activity. ${ }^{95}$ Also, in open chain low rowing exercises, a unilateral stance on the contralateral leg increases scapular muscle activity and improves the UT/LT ratio, whereas sitting positions and a bilateral stance seem to be not favourable for optimal scapular muscle balance. ${ }^{88}$ In summary, it seems that diagonal patterns including lower limb and core muscle activity are in favour of scapular muscle activity, particularly in LT.

In addition to these basic exercises, it is important that overhead athletes may gradually perform functional diagonals into internal and external rotation with increasing intensity and load and accurate scapular muscle control, in preparation of the third sport-specific stage of scapular muscle rehabilitation.

\section{Third stage: advanced control during sports movements}

Once muscle balance is restored, in the third stage of scapular muscle rehabilitation, general scapular strengthening exercises may be used to increase muscle strength. Numerous studies propose optimal strengthening exercises for the scapular muscles, but a detailed description of all these exercises goes beyond the scope of this paper. ${ }^{100} 103107$ In this last stage of scapular rehabilitation, in which the treatment goal is to exercise advanced scapular muscle control and strength during sport-specific movements, special attention is given to integration of the kinetic chain into the exercise programme, implementation of sport-specific demands by performing plyometric exercises and eccentric exercises. ${ }^{15} 108$ Scapular control should be automated and integrated into all sport-specific exercises. Throwing athletes should perform exercises in which the external rotators are eccentrically loaded, for instance, using weight balls and elastic resistance-tubing. ${ }^{15} 63$ On the other hand, swimmers should not focus on plyometrics, but rather train in sport-specific positions such as lying prone or supine in situations demanding a lot of core stability. An interesting exercise is the so-called $\mathrm{W}-\mathrm{V}$ exercise, in which the patient is prone on a Swiss ball and performs movements, forming a ' $\mathrm{W}$ ' and a ' $\mathrm{V}$ ' with his arms. Gymnasts and athletes performing climbing sports should perform high-level closed chain exercises such as side-bridging and prone-bridging, and sling-exercises might be added to their programme. ${ }^{109}$

There are no science-based guidelines for return to play (RTP) in overhead athletes with shoulder and neck dysfunction. Although a general decision-based RTP model has been published, ${ }^{110}$ specific guidelines and cut-point values for the medical factors at the shoulder girdle to be evaluated in step 
one (evaluation of the health status) are scarce. As a result, each clinician uses normative data from the literature, or his own clinical reasoning process to decide whether an athlete is ready to play. Ideal return-to-play criteria are described by Mc Carty et $a l^{111}$ comprising little/no pain, subjective satisfaction of the treatment by the patient, near normal ROM and strength, and normal functional ability and sport-specific skills. Regarding scapular dyskinesis, we recommend symmetry in the scapular muscle strength in athletes not performing throwing sports, and $10 \%$ increased strength on the dominant side in unilateral overhead sports (isometric muscle strength, measured with a Hand-Held Dynamometer). ${ }^{112}$ Special attention should be given to the strength of the middle and lower portions of the trapezius. ${ }^{37}$ Based on values in a normal non-injured population, a ratio of $100 \%$ is recommended between the protractors and retractors, measured isokinetically. ${ }^{48} 113$ For flexibility variables, a pectoralis minor index (pectoralis minor length normalised for body height) of 8.61 is advised, ${ }^{40}$ along with less than a $20^{\circ}$ side difference for internal rotation range of motion, ${ }^{32}$ or a $10 \%$ side difference in the total ROM (ER+IR). ${ }^{15}$ Finally, although there is no validated standardised RTP play test, the clinician can use specific functional fatigue tests to assist him in the decision to return to play, such as a high performance plyometric test, or an eccentric test for the rotator cuff muscles.

Once the athlete is back on the field, we recommend continuing the stretching of the pectoralis minor and posterior shoulder structures, and the rotator cuff and MT and LT should be strengthened in a preventive programme with respect to chronic overuse shoulder pain.

\section{SCIENTIFIC RATIONALE FOR A SCAPULAR REHABILITATION PROGRAMME}

Recently, several studies have examined the effectiveness of a scapula-based rehabilitation programme. ${ }^{75}{ }^{114-120}$ Vande Velde et $a l^{116}$ showed that a 12 -week scapular training programme resulted in a significant increase in isokinetic scapular muscle strength in healthy adolescent swimmers, and from a study of Merolla et $a l,{ }^{117}$ strength increase in the glenohumeral external rotators was apparent after a 6-month training programme in volleyball players with scapular dyskinesis. The latter study is of particular importance since it showed that scapular training improved glenohumeral muscle function, specifically the external rotators which are highly stressed during overhead activities. However, both the studies mentioned were performed on healthy non-injured overhead athletes. Recently, De Mey et $a l^{119}$ showed that after 6 weeks of training according to the method described by Cools et al, ${ }^{102}$ overhead athletes with impingement symptoms showed improved scapular muscle recruitment. In this study, surface EMG activity was recorded from the four major scapular muscles before and after the training programme. The main result was that the relative muscle activity for UT during arm elevation significantly decreased compared to the pretraining test and compared to the other scapular muscles. In view of the assumption that UT is often overactive in patients with impingement, a decrease in activity implicates a more efficient scapular recruitment pattern. ${ }^{37}$ In addition, SPADI scores showed significant functional improvement and less pain after completing the scapula-based exercise programme. A few randomised controlled trials confirmed the value of scapular exercises in the treatment of shoulder impingement. ${ }^{75}{ }^{120}$ In general, these studies show better results regarding functional outcome, strength and patient satisfaction if a scapular approach is implemented in the treatment protocol.
However, further research is required to show that restoring scapular control directly influences shoulder and neck pain.

\section{CONCLUSION}

In summary, there is evidence of scapular kinematic alterations associated with shoulder and neck pain. There is also evidence of altered scapular muscle recruitment patterns in these patients, with respect to changes in strength, flexibility, motor control and timing of the surrounding muscles. In particular, lack of flexibility, in combination with muscle dysfunction of SA and LT, might be the clinical base for a treatment programme given to these patients. The available evidence in clinical trials supports the use of therapeutic exercise in the rehabilitation of these patients; however, future studies should be performed to confirm the effectiveness of these exercise protocols.

\section{Summary}

- The scapula functions as a bridge between the shoulder complex and the cervical spine.

- Although the association between abnormal scapular positions and motions and glenohumeral joint pathology has been well established in the literature, studies investigating the relationship between neck pain and scapular dysfunction have only recently begun to emerge.

- Overall, scapular rehabilitation guidelines decent for both patients with shoulder pain as well as patients with neck problems are lacking.

- A science-based clinical reasoning algorithm with practical guidelines is provided which may help the clinician to put the rehabilitation of scapular dyskinesis into a precise perspective of the thorough treatment of shoulder and/or neck dysfunction.

Contributors AMJC has substantially contributed to the conception and design of the manuscript, drafting of the article and final approval of the manuscript. She is responsible for the overall content as guarantor. FS, KDM, AM, BC and BCG has substantially contributed to the drafting, revision and final approval of the manuscript. BCG has also contributed to the conception and design of the manuscript. She is also responsible for the overall content as a Guarantor.

Competing interests None.

Provenance and peer review Commissioned; externally peer reviewed.

\section{REFERENCES}

1 Van der Windt DA, Koes BW, De Jong BA, et al. Shoulder disorders in genera practice: incidence, patient characteristics, and management. Ann Rheum Dis 1995;54:959-64.

2 Bot SD, Van der Waal JM, Terwee CB, et al. Incidence and prevalence of complaints of the neck and upper extremity in general practice. Ann Rheum Dis 2005;64:118-23.

3 Picavet HS, Hazes JM. Prevalence of self reported musculoskeletal diseases is high. Ann Rheum Dis 2003;62:644-50.

4 Gerr F, Marcus M, Monteilh C. Epidemiology of musculoskeletal disorders among computer users: lesson learned from the role of posture and keyboard use. J Electromyogr Kinesiol 2004;14:25-31.

5 Lintner D, Noonan TJ, Kibler WB. Injury patterns and biomechanics of the athlete's shoulder. Clin Sports Med 2008;27:527-51.

6 Kibler WB. The role of the scapula in athletic shoulder function. Am J Sports Med 1998:26:325-37

7 Mottram SL. Dynamic stability of the scapula. Man Ther 1997:2:123-31.

8 Kamkar A, Irrgang JJ, Whitney SL. Nonoperative management of secondary shoulder impingement syndrome. J Orthop Sports Phys Ther 1993;17:212-24.

9 Ludewig PM, Reynolds JF. The association of scapular kinematics and glenohumeral joint pathologies. J Orthop Sports Phys Ther 2009;39:90-104. 
10 Kibler WB, Sciascia A. Current concepts: scapular dyskinesis. Br J Sports Med 2010;44:300-5

11 Behrsin JF, Maguire K. Levator scapulae action during shoulder movement: a possible mechanism for shoulder pain of cervical origin. Aust J Physiother 1986:32:101-6.

12 Jull G, Sterling M, Falla D, et al. Whiplash, headache and neck pain. 1st edn. Churchill Livingstone, 2008.

13 Ludewig PM, Braman JP. Shoulder impingement: biomechanical considerations in rehabilitation. Man Ther 2011;16:33-9.

14 Struyf F, Nijs J, Mottram S, et al. Clinical assessment of the scapula: a review of the literature. Br J Sports Med Published Online First: 21 July 2012. doi:10.1136/ bjsports-2012-091059

15 Ellenbecker TS, Cools A. Rehabilitation of shoulder impingement syndrome and rotator cuff injuries: an evidence-based review. Br J Sports Med 2010;44:319-27.

16 Cools AM, Declercq G, Cagnie B, et al. Internal impingement in the tennis player: rehabilitation guidelines. Br J Sports Med 2008;42:165-71.

17 Forthomme B, Crielaard JM, Croisier JL. Scapular positioning in athlete's shoulder: particularities, clinical measurements and implications. Sports Med 2008;38:369-86

18 Jaggi A, Lambert S. Rehabilitation for shoulder instability. Br J Sports Med 2010;44:333-40

19 O'leary S, Falla D, Elliott JM, et al. Muscle dysfunction in cervical spine pain: implications for assessment and management. J Orthop Sports Phys Ther 2009;39:324-33.

20 Ludewig PM, Cook TM. Alterations in shoulder kinematics and associated muscle activity in people with symptoms of shoulder impingement. Phys Ther 2000;80:276-91.

21 Laudner KG, Myers JB, Pasquale MR, et al. Scapular dysfunction in throwers with pathologic internal impingement. J Orthop Sports Phys Ther 2006:36:485-94

22 Hebert L, Moffet $\mathrm{H}, \mathrm{McFadyen} B J$, et al. Scapular behavior in shoulder impingement syndrome. Arch Phys Med Rehabil 2002;83:60-9.

23 Lin JJ, Hanten WP, Olson SL, et al. Functional activity characteristics of individuals with shoulder dysfunctions. J Electromyogr Kinesiol 2005;15:576-86.

24 McClure PW, Michener LA, Karduna AR. Shoulder function and 3-dimensional scapular kinematics in people with and without shoulder impingement syndrome. Phys Ther 2006;86:1075-90

25 Illyes A, Kiss RM. Kinematic and muscle activity characteristics of multidirectional shoulder joint instability during elevation. Knee Surg Sports Traumatol Arthrosc 2006;14:673-85.

26 Ogston JB, Ludewig PM. Differences in 3-dimensional shoulder kinematics between persons with multidirectional instability and asymptomatic controls. Am J Sports Med 2007:35:1361-70.

27 Warner JJ, Micheli LJ, Arslanian LE, et al. Scapulothoracic motion in norma shoulders and shoulders with glenohumeral instability and impingement syndrome. A study using Moire topographic analysis. Clin Orthop Relat Res 1992;285:191-9.

28 Kibler WB, Ludewig PM, McClure P, et al. Scapular Summit 2009: introduction. 16 July, 2009, Lexington, Kentucky. J Orthop Sports Phys Ther 2009;39:A1-13.

29 Szeto GP, Straker L, Raine S. A field comparison of neck and shoulder postures in symptomatic and asymptomatic office workers. App/ Ergon 2002;33:75-84.

30 Kebaetse $M$, McClure $P$, Pratt NA. Thoracic position effect on shoulder range of motion, strength, and three-dimensional scapular kinematics. Arch Phys Med Rehabil 1999;80:945-50.

31 Finley MA, Lee RY. Effect of sitting posture on 3-dimensional scapular kinematics measured by skin-mounted electromagnetic tracking sensors. Arch Phys Med Rehabil 2003;84:563-8.

32 Kibler WB. Rehabilitation of rotator cuff tendinopathy. Clin Sports Med 2003;22:837-47

33 Helgadottir H, Kristjansson E, Mottram S, et al. Altered scapular orientation during arm elevation in patients with insidious onset neck pain and whiplash-associated disorder. J Orthop Sports Phys Ther 2010;40:784-91.

34 Helgadottir $\mathrm{H}$, Kristjansson $\mathrm{E}$, Mottram $\mathrm{S}$, et al. Altered alignment of the shoulder girdle and cervical spine in patients with insidious onset neck pain and whiplash-associated disorder. J App/ Biomech 2011:27:181-91.

35 Cools AM, Witvrouw EE, Declercq GA, et al. Scapular muscle recruitment patterns: trapezius muscle latency with and without impingement symptoms. Am J Sports Med 2003;31:542-9.

36 Cools AM, Witvrouw EE, Declercq GA, et al. Evaluation of isokinetic force production and associated muscle activity in the scapular rotators during a protraction-retraction movement in overhead athletes with impingement symptoms Br J Sports Med 2004;38:64-8.

37 Cools AM, Declercq GA, Cambier DC, et al. Trapezius activity and intramuscular balance during isokinetic exercise in overhead athletes with impingement symptoms. Scand J Med Sci Sports 2007;17:25-33.

38 Borstad JD, Mathiowetz KM, Minday LE, et al. Clinical measurement of posterio shoulder flexibility. Man Ther 2007;12:386-9.
39 Borich MR, Bright JM, Lorello DJ, et al. Scapular angular positioning at end range internal rotation in cases of glenohumeral internal rotation deficit. J Orthop Sports Phys Ther 2006;36:926-34.

40 Borstad JD, Ludewig PM. The effect of long versus short pectoralis minor resting length on scapular kinematics in healthy individuals. J Orthop Sports Phys Ther 2005:35:227-38.

41 Borstad JD. Resting position variables at the shoulder: evidence to support a posture-impairment association. Phys Ther 2006;86:549-57.

42 Tyler TF, Nicholas SJ, Roy T, et al. Quantification of posterior capsule tightness and motion loss in patients with shoulder impingement. Am J Sports Med 2000;28:668-73.

43 Tyler TF, Nicholas SJ, Lee SJ, et al. Correction of posterior shoulder tightness is associated with symptom resolution in patients with internal impingement. Am J Sports Med 2010:38:114-19.

44 Reeser JC, Joy EA, Porucznik CA, et al. Risk factors for volleyball-related shoulder pain and dysfunction. PM R 2010;2:27-36.

45 Tate A, Turner GN, Knab SE, et al. Risk factors associated with shoulder pain and disability across the lifespan of competitive swimmers. J Athl Train 2012:47:149-58.

46 Wilk KE, Macrina LC, Fleisig GS, et al. Correlation of glenohumeral internal rotation deficit and total rotational motion to shoulder injuries in professional baseball pitchers. Am J Sports Med 2011;39:329-35.

47 Shanley E, Rauh MJ, Michener LA, et al. Shoulder range of motion measures as risk factors for shoulder and elbow injuries in high school softball and baseball players. Am J Sports Med 2011;39:1997-2006.

48 Cools AM, Witvrouw EE, Mahieu NN, et al. Isokinetic scapular muscle performance in overhead athletes with and without impingement symptoms. J Athl Train 2005;40:104-10.

49 Cools AM, Geerooms E, Van den Berghe DF, et al. Isokinetic scapular muscle performance in young elite gymnasts. J Athl Train 2007;42:458-63.

50 Moraes GF, Faria CD, Teixeira-Salmela LF. Scapular muscle recruitment patterns and isokinetic strength ratios of the shoulder rotator muscles in individuals with and without impingement syndrome. J Shoulder Elbow Surg 2008;17(1 Suppl):48S-53S.

51 Wadsworth DJ, Bullock-Saxton JE. Recruitment patterns of the scapular rotator muscles in freestyle swimmers with subacromial impingement. Int I Sports Med 1997; 18:618-24.

52 Falla D, Bilenkii G, Jull G. Patients with chronic neck pain demonstrate altered patterns of muscle activation during performance of a functional upper limb task. Spine (Phila Pa 1976) 2004;29:1436-40

53 Nederhand MJ, lizerman MJ, Hermens HJ, et al. Cervical muscle dysfunction in the chronic whiplash associated disorder grade II (WAD-II). Spine 2000;25:1938-43.

54 Szeto GP, Straker LM, O'Sullivan PB. A comparison of symptomatic and asymptomatic office workers performing monotonous keyboard work-1: neck and shoulder muscle recruitment patterns. Man Ther 2005;10:270-80.

55 Johnston $\mathrm{V}$, Jull $\mathrm{G}$, Souvlis $\mathrm{T}$, et al. Neck movement and muscle activity characteristics in female office workers with neck pain. Spine (Phila Pa 1976) 2008:33:555-63.

56 Johnston $V$, Jull G, Darnell $R$, et al. Alterations in cervical muscle activity in functional and stressful tasks in female office workers with neck pain. Eur J Appl Physiol 2008:103:253-64.

57 Falla D, Farina D, Graven-Nielsen T. Experimental muscle pain results in reorganization of coordination among trapezius muscle subdivisions during repetitive shoulder flexion. Exp Brain Res 2007;178:385-93.

58 Zakharova-Luneva $\mathrm{E}$, Jull G, Johnston $\mathrm{V}$, et al. Altered trapezius muscle behavior in individuals with neck pain and clinical signs of scapular dysfunction. J Manipulative Physiol Ther 2012;35:346-53.

59 Wegner $\mathrm{S}$, Jull G, O'leary $\mathrm{S}$, et al. The effect of a scapular postural correction strategy on trapezius activity in patients with neck pain. Man Ther 2010;15:562-6.

60 Helgadottir $H$, Kristjansson $E$, Einarsson $E$, et al. Altered activity of the serratus anterior during unilateral arm elevation in patients with cervical disorders. J Electromyogr Kinesiol 2011;21:947-53.

61 Sheard B, Elliott J, Cagnie B, et al. Evaluating serratus anterior muscle function in neck pain using muscle functional magnetic resonance imaging. J Manipulative Physiol Ther 2012;35:629-35.

62 Oyama $\mathrm{S}$, Myers JB, Wassinger CA, et al. Asymmetric resting scapular posture in healthy overhead athletes. J Athl Train 2008:43:565-70.

63 Myers JB, Laudner KG, Pasquale MR, et al. Scapular position and orientation in throwing athletes. Am J Sports Med 2005;33:263-71.

64 Laudner KG, Stanek JM, Meister K. Differences in scapular upward rotation between baseball pitchers and position players. Am J Sports Med 2007:35:2091-5.

65 Silva RT, Hartmann LG, Laurino CF, et al. Clinical and ultrasonographic correlation between scapular dyskinesia and subacromial space measurement among junior elite tennis players. Br J Sports Med 2010;44:407-10. 
66 Cools AM, Johansson FR, Cambier DC, et al. Descriptive profile of scapulothoracic position, strength and flexibility variables in adolescent elite tennis players. $\mathrm{Br} J$ Sports Med 2010;44:678-84.

67 Kawasaki T, Yamakawa J, Kaketa T, et al. Does scapular dyskinesis affect top rugby players during a game season?. J Shoulder Elbow Surg 2012;21:709-14.

68 Hodges PW, Tucker K. Moving differently in pain: a new theory to explain the adaptation to pain. Pain 2011;152(3 Suppl):S90-8.

69 Sciascia A, Thigpen C, Namdari S, et al. Kinetic chain abnormalities in the athletic shoulder. Sports Med Arthrosc 2012;20:16-21.

70 Sciascia A, Cromwell R. Kinetic chain rehabilitation: a theoretical framework. Rehabil Res Pract 2012;2012:853037.

71 Borstad JD, Ludewig PM. Comparison of three stretches for the pectoralis minor muscle. J Shoulder Elbow Surg 2006;15:324-30.

72 Muraki T, Aoki M, Izumi T, et al. Lengthening of the pectoralis minor muscle during passive shoulder motions and stretching techniques: a cadaveric biomechanical study. Phys Ther 2009;89:333-41.

73 Meister K, Buckley B, Batts J. The posterior impingement sign: diagnosis of rotator cuff and posterior labral tears secondary to internal impingement in overhand athletes. Am J Orthop 2004;33:412-15.

74 Hanten WP, Olson SL, Butts NL, et al. Effectiveness of a home program of ischemic pressure followed by sustained stretch for treatment of myofascial trigger points. Phys Ther 2000;80:997-1003.

75 Struyf F, Nijs J, Mollekens S, et al. Scapular-focused treatment in patients with shoulder impingement syndrome: a randomized clinical trial. Clin Rheumatol 2012:32:73-85.

76 Gulick DT, Palombaro K, Lattanzi JB. Effect of ischemic pressure using a Backnobber II device on discomfort associated with myofascial trigger points. J Bodyw Mov Ther 2011;15:319-25.

77 Hidalgo-Lozano A, Fernandez-de-Las-Penas C, Diaz-Rodriguez L, et al. Changes in pain and pressure pain sensitivity after manual treatment of active trigger points in patients with unilateral shoulder impingement: a case series. J Bodyw Mov Ther 2011:15:399-404.

78 Laudner KG, Sipes RC, Wilson JT. The acute effects of sleeper stretches on shoulder range of motion. J Athl Train 2008:43:359-63.

79 McClure $\mathrm{P}$, Balaicuis J, Heiland $\mathrm{D}$, et al. A randomized controlled comparison of stretching procedures for posterior shoulder tightness. J Orthop Sports Phys Ther 2007:37:108-14

80 Maenhout A, Van EV, Van DL, et al. Quantifying acromiohumeral distance in overhead athletes with glenohumeral internal rotation loss and the influence of a stretching program. Am J Sports Med 2012;40:2105-12.

81 Manske RC, Meschke M, Porter A, et al. A randomized controlled single-blinded comparison of stretching versus stretching and joint mobilization for posterior shoulder tightness measured by internal rotation motion loss. Sports Health 2010;2:94-100

82 Cools AM, Johansson FR, Cagnie B, et al. Stretching the posterior shoulder structures in subjects with internal rotation deficit: comparison of two stretching techniques. Shoulder Elbow 2012;4:56-63.

83 Mottram SL, Woledge RC, Morrissey D. Motion analysis study of a scapular orientation exercise and subjects' ability to learn the exercise. Man Ther 2009:14:13-18.

84 Wegner S, Jull G, O'Leary S, et al. The effect of a scapular postural correction strategy on trapezius activity in patients with neck pain. Man Ther 2010;15:562-6

85 Roy JS, Moffet H, McFadyen BJ. Upper limb motor strategies in persons with and without shoulder impingement syndrome across different speeds of movement. Clin Biomech (Bristol, Avon) 2008:23:1227-36.

86 Roy JS, Moffet $\mathrm{H}$, Hebert $\mathrm{L}$, et al. Effect of motor control and strengthening exercises on shoulder function in persons with impingement syndrome: a single-subject study design. Man Ther 2009;14:180-8

87 Holtermann A, Mork PJ, Andersen LL, et al. The use of EMG biofeedback for learning of selective activation of intra-muscular parts within the serratus anterior muscle: a novel approach for rehabilitation of scapular muscle imbalance. J Electromyogr Kinesiol 2010;20:359-65.

88 De Mey K, Danneels L, Cagnie B, et al. Kinetic chain influences on upper and lower trapezius muscle activation during eight variations of a scapular retraction exercise in overhead athletes. I Sci Med Sport 2013;16:65-70.

89 Falla D, O'Leary S, Fagan A, et al. Recruitment of the deep cervical flexor muscles during a postural-correction exercise performed in sitting. Man Ther 2007;12:139-43.

90 Lewis JS, Wright C, Green A. Subacromial impingement syndrome: the effect of changing posture on shoulder range of movement. J Orthop Sports Phys Ther 2005:35:72-87.

91 Kibler WB, Sciascia AD, Uhl TL, et al. Electromyographic analysis of specific exercises for scapular control in early phases of shoulder rehabilitation. Am J Sports Med 2008;36:1789-98.
92 Uhl TL, Carver TJ, Mattacola CG, et al. Shoulder musculature activation during upper extremity weight-bearing exercise. J Orthop Sports Phys Ther 2003;33:109-17.

93 Lephart S, Fu F. Proprioception and neuromuscular control in joint stability. 1st edn. Human Kinetics, 2000.

94 Ludewig PM, Hoff MS, Osowski EE, et al. Relative balance of serratus anterior and upper trapezius muscle activity during push-up exercises. Am I Sports Med 2004;32:484-93.

95 Maenhout A, Van PK, Pizzi L, et al. Electromyographic analysis of knee push up plus variations: what is the influence of the kinetic chain on scapular muscle activity? Br J Sports Med 2010;44:1010-15.

96 Hardwick DH, Beebe JA, McDonnell MK, et al. A comparison of serratus anterior muscle activation during a wall slide exercise and other traditional exercises. J Orthop Sports Phys Ther 2006;36:903-10.

97 Lunden JB, Braman JP, Laprade RF, et al. Shoulder kinematics during the wall push-up plus exercise. J Shoulder Elbow Surg 2010;19:216-23.

98 Tucker WS, Campbell BM, Swartz EE, et al. Electromyography of 3 scapular muscles: a comparative analysis of the cuff link device and a standard push-up. J Athl Train 2008;43:464-9.

99 De Oliveira AS, De Morais CM, De Brum DP. Activation of the shoulder and arm muscles during axial load exercises on a stable base of support and on a medicine ball. J Electromyogr Kinesiol 2008;18:472-9.

100 Moseley JB Jr, Jobe FW, Pink M, et al. EMG analysis of the scapular muscles during a shoulder rehabilitation program. Am I Sports Med 1992;20:128-34.

101 Uhl TL, Muir TA, Lawson L. Electromyographical assessment of passive, active assistive, and active shoulder rehabilitation exercises. Phys Med Rehabil 2010:2:132-41.

102 Cools AM, Dewitte V, Lanszweert F, et al. Rehabilitation of scapular muscle balance: which exercises to prescribe? Am J Sports Med 2007:35:1744-51.

103 Reinold MM, Escamilla RF, Wilk KE. Current concepts in the scientific and clinical rationale behind exercises for glenohumeral and scapulothoracic musculature. J Orthop Sports Phys Ther 2009;39:105-17.

104 Cools AM, Dewitte V, Lanszweert F, et al. Rehabilitation of scapular muscle balance: which exercises to prescribe? Am J Sports Med 2007:35:1744.

105 De Mey K, Cagnie B, Danneels LA, et al. Trapezius muscle timing during selected shoulder rehabilitation exercises. J Orthop Sports Phys Ther 2009:39:743-52.

106 Decker MJ, Hintermeister RA, Faber KJ, et al. Serratus anterior muscle activity during selected rehabilitation exercises. Am J Sports Med 1999:27:784-91.

107 Wilk KE, Yenchak AJ, Arrigo CA, et al. The advanced throwers ten exercise program: a new exercise series for enhanced dynamic shoulder control in the overhead throwing athlete. Phys Sports Med 2011;39:90-7.

108 Carter AB, Kaminski TW, Douex AT Jr, et al. Effects of high volume upper extremity plyometric training on throwing velocity and functional strength ratios of the shoulder rotators in collegiate baseball players. I Strength Cond Res 2007;21:208-15.

109 Dannelly BD, Otey SC, Croy T, et al. The effectiveness of traditional and sling exercise strength training in women. J Strength Cond Res 2011:25:464-71.

110 Matheson GO, Shultz R, Bido J, et al. Return-to-play decisions: are they the team physician's responsibility? Clin I Sport Med 2011;21:25-30.

111 McCarty EC, Ritchie P, Gill HS, et al. Shoulder instability: return to play. Clin Sports Med 2004;23:335-viii.

112 Ellenbecker TS, Davies GJ. The application of isokinetics in testing and rehabilitation of the shoulder complex. J Athl Train 2000;35:338-50.

113 Cools AM, Witvrouw EE, De Clerca GA, et al. Scapular muscle recruitment pattern: electromyographic response of the trapezius muscle to sudden shoulder movement before and after a fatiguing exercise. J Orthop Sports Phys Ther 2002:32:221-9.

114 Tate AR, McClure PW, Young IA, et al. Comprehensive impairment-based exercise and manual therapy intervention for patients with subacromial impingement syndrome: a case series. J Orthop Sports Phys Ther 2010;40:474-93.

115 Seitz AL, McClure PW, Finucane S, et al. The scapular assistance test results in changes in scapular position and subacromial space but not rotator cuff strength in subacromial impingement. J Orthop Sports Phys Ther 2012;42:400-12.

116 Van de velde A, De Mey K, Maenhout A, et al. Scapular-muscle performance: two training programs in adolescent swimmers. J Athl Train 2011;46:160-7.

117 Merolla G, De SE, Sperling JW, et al. Infraspinatus strength assessment before and after scapular muscles rehabilitation in professional volleyball players with scapular dyskinesis. J Shoulder Elbow Surg 2010;19:1256-64.

118 Merolla G, De SE, Campi F, et al. Supraspinatus and infraspinatus weakness in overhead athletes with scapular dyskinesis: strength assessment before and after restoration of scapular musculature balance. Musculoskelet Surg 2010;94:119-25.

119 De Mey K, Danneels L, Cagnie B, et al. Scapular muscle rehabilitation exercises in overhead athletes with impingement symptoms: effect of a 6-week training program on muscle recruitment and functional outcome. Am I Sports Med 2012:40:1906-15.

120 Holmgren T, Bjornsson HH, Oberg B, et al. Effect of specific exercise strategy on need for surgery in patients with subacromial impingement syndrome: randomised controlled study. BMJ 2012;344:e787. 